九州大学学術情報リポジトリ

Kyushu University Institutional Repository

Water Relations Characteristics of Cryp tomeria japonica D. Don. (VI) : A Simulation Model of Water Regime Using the Parameters Obtained by the P-V Curve Technique

Yahata, Hisashi

Laboratory of Silviculture, Faculty of Agriculture Kyushu University

https://doi.org/10.5109/23847

出版情報 : 九州大学大学院農学研究院紀要. 31 (3)，pp.235-245，1987-03-10. Kyushu University バージョン：

権利関係 : 


\title{
Water Relations Characteristics of Cryp tomeria japonica D. Don.(VI) \\ A Simulation Model of Water Regime Using the Parameters Obtained by the P-V Curve Technique
}

\author{
Hisashi Yahata* \\ Laboratory of Silviculture, Faculty of Agriculture \\ Kyushu University 46-03, Fukuoka 812
}

(Received July 31, 1986)

\begin{abstract}
A simulation model on water regime of trees was constructed with a use of equations concerning some water relations parameters of leaves measured by pressure-volume (P-V) curve technique and was used to compare the effects of parameters on water regime among 8 cultivars of Cryptomeria japonica under some assumptions. Simulated results showed as follows : owing to the function of leaves as a water reservoir water flow from soil to leaves occurred behind the transpiration and time lag increased when the water flow resistance increased and the pattern of changes of water potential, transpiration, and water flow, respectively, differed between the forenoon and afternoon even though the environments were set symmetrical between them. The drier soil became, i. e. the more negative the soil water potential was, the greater a cultivar Urasebaru, the leaves of which had the higher osmotic potential at full turgor, and Kumotooshi decreased the transpiration rate compared to the other cultivars such as Kijin, Yabukuguri, Iwao, and Yaichi. The simulated effect of the drought on the transpiration was approximately supported by the another experiment. The low resistance to drought of Urasebaru approximately agreed with the growth response in practical fields which is reportedly very sensitive to the site quality. The model could contribute to early test in tree breeding.
\end{abstract}

\section{INTRODUCTION}

Cryptomeria japonica (sugi) is one of the most useful and famous species for forestry, especially for its propagation by cuttings in the island of Kyushu. There are about 60 cultivars of Cryptomeria japonica cultivated in Kyushu (Sato et al., 1971) and they are planted in the relatively moist site compared to other species such as Chamaechyparis obtusa (hinoki) and Pinus species. Therefore, as an early test for tree breeding, it is more useful to determine physiological and morphological factors which may permit species to maintain longer periods of net $\mathrm{CO}_{2}$ assimilation in the drier soil condition than to know the factors for drought avoidance, by which trees can survive in the severe drought. It is reported that there are some cultivars which do not grow well in a poor site compared to the other cultivars. In other words, some cultivars have a very sensitive response to the site quality of plantation. There might be a number of physiological factors which will cause the sensitivity differences. Among many other physiological factors, the physiological responses to drought must be one of the 
most important factors as well as the one to soil nutrients.

There is an advantage in determining the various physiological response of the cultivars because they are considered to be monoclones and the data obtained will be available in the practical fields. Therefore, in another report (Yahata, 1978, 1979, unpublished), the author tried to determine and find the differences of water relations parameters of the leaves which would affect the responses to dry condition. A number of parameters can be obtained for a single leaf or shoot by the pressure volume curve technique (P-V curve technique) developed by Tyree and Hammel (1972). The technique could be applied also to Cryptomeria japonica (Yahata, 1978), and a number of parameters of the leaves were obtained ; for instance, the osmotic potential at full turgor $(\Psi \circ 0)$, the water potential at turgor loss point $\left(\Psi l^{*}\right)$, the volume of symplastic water both at full turgor $(\mathbf{V o})$ and at turgor loss point $(V p)$ and the water content at full turgor $\left(W_{s}\right)$. They showed some significant differences among some cultivars (Yahata, unpublished). Although it is possible to explain the role of each parameter in the water regime, it is not easy to explain how much these parameters have effects on the result in the whole trees under specific meteorological conditions. Therefore it is necessary to establish a simulation model that can help interpret the effect of the water relations parameters of the leaves on the water regime inside trees.

In this report, the series of equations and the solving procedures are presented as a computer simulation model, and an application of the data of 8 cultivars of Cryptomeria japonica under some assumptions.

\section{SIMULATION MODEL}

The concept and outline of the simulation model constructed here is shown in Fig. 1. In this model, to compare the effect of the leaf water relations parameters among cultivars, artificial plantations of Cryptomeria japonica with dry weight of leaves per

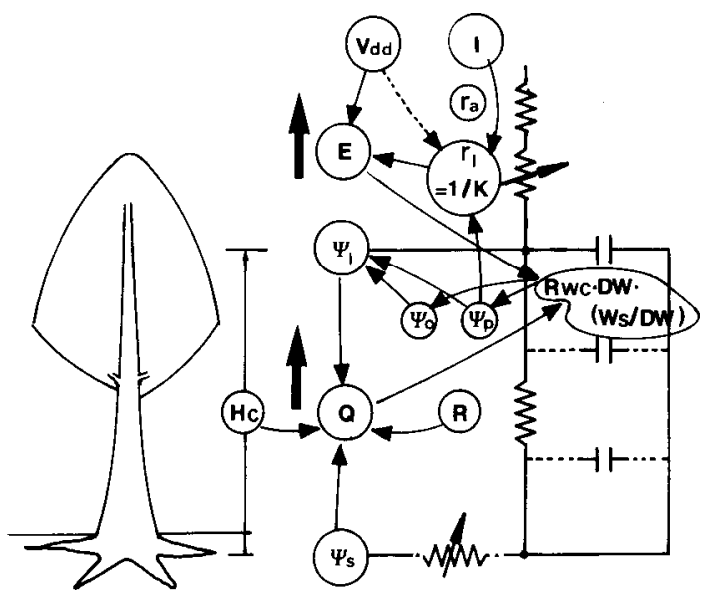

Fig. 1. Illustration of concept and outline of the simulation model. Arrows indicate the direction of influence of factors. The factors and influence shown in dotted lines are not considered in the present report. 
unit land area, $D w\left(\mathrm{~kg} / \mathrm{m}^{2}\right)$, and similar diameter and tree density among the cultivars are assumed. To simplify the analysis, it is also assumed that single values of water potential, leaf diffusive conductance, and water relations parameters can represent the whole canopy. The transpiration rate per unit leaf area is,

$$
E^{\prime}=(D(T l)-D(T a) \cdot R h) /\left(r_{a}+r_{l}\right),
$$

where $E^{\prime}$ is the transpiration rate per unit leaf area $\left(\mathrm{kg} /\left(\mathrm{m}^{2} \cdot \mathrm{s}\right)\right) ; D(T)$ is the water vapor density at the temperature $T^{\circ} \mathrm{C}\left(\mathrm{kg} / \mathrm{m}^{3}\right) ; T a$ and $T l$ are the air and leaf temperature $\left({ }^{\circ} \mathrm{C}\right) ; r_{a}$ is the leaf boundary resistance $(\mathrm{s} / \mathrm{m}) ; r_{l}$ is the leaf diffusive resistance for water vapor $(\mathrm{s} / \mathrm{m})$.

In Eq. 1, $r_{a}$ is considered to change by the effects of leaf shapes and wind speeds. It is also reported, however, that $r_{a}$ becomes much less than $r_{l}$ in the coniferous forests such as Douglas-fir because of the greater wind speeds (usually much greater than 0.9 $\mathrm{m} / \mathrm{s}$ ) and the thin and small shape of leaves (Tan et al., 1978). Therefore, neglecting $r_{a}$ does not seem to lead to noticeable error in estimating the transpiration rates. The leaf conductance $(K)$ is equal to the inverse of diffusive resistance and the unit of $K$ is expressed as $\mathrm{m}^{3} /(\mathrm{kgDw} \cdot \mathrm{s})$ when the unit of the transpiration rate is based on the leaf dry weight. Under the condition mentioned above, leaf temperature is usually very close to that of air. Then, under the condition of $T l=T a$, the difference of water vapor densities from the leaf cavity to the atmospheric air $\left(V d d, \mathrm{~kg} / \mathrm{m}^{3}\right)$ can be expressed as follows :

$V d d=D(T l)-D(T a) \cdot R h=D(T a) \cdot(1-R h)$.

Transpiration rate from the forest canopy per unit area $\left(E, \mathrm{~kg} /\left(\mathrm{m}^{2} \cdot \mathrm{s}\right)\right)$ is

$E=K \cdot V d d \cdot D w$.

On the other hand, it is explained on the basis of the thermodynamics that water movement occurs spontaneously from a region of higher water potential to one of lower water potential according to the gradient of water potential. In case of trees, the gradient of total water potentials between leaves and soil is reduced by the difference of height. Then, the water flow rate per unit area of land $\left(\mathrm{Q}, \mathrm{kg} /\left(\mathrm{m}^{2} \cdot \mathrm{s}\right)\right)$ is determined by the following equation.

$$
\text { - } Q=(\Psi s-\Psi l-\rho \cdot g \cdot H c) / R \text {, }
$$

where $R$ is the total values of resistance to water flow from the soil to the root surface and from root surface up to the canopy at a height of $H c(\mathrm{~m})$ above water in the root zone ; $\Psi s$ and $\Psi l$ are the water potentials of soil and leaves (MPa), respectively; $\rho \cdot$ $g \cdot H c$ is the gravitational potential (a product of the density of water, the gravity constant, and the height above water in the root zone, respectively, and $\rho \cdot g$ is equal to $\left.9.807 \times 10^{-3} \mathrm{MPa} / \mathrm{m}\right)$.

Leaf water potential $(\Psi l, \mathrm{MPa})$ is determined by the following equation.

$$
\Psi l=\Psi o+\Psi p
$$

where $\Psi o$ and $\Psi p$ are the osmotic potential and (turgor) pressure potential of the leaf, respectively $(\mathrm{MPa})$. The values of $\Psi O$ are obtainable by the $\mathrm{P}-\mathrm{V}$ curve technique and expressed as

$$
\Psi o=-\left(V_{o}-V e\right) / R T N s
$$

where $R$ is the gas constant ; $T$ is Kelvin temperature ${ }^{\circ} \mathrm{K} ; N s$ is the number of moles of solute in the symplastic water; $V o$ is the volume of symplastic water at full turgor ; and $V e$ is the volume of expressed water from the leaf by the applied pressure $\mathbf{P}$.

As these variables are dependent on the size of sample leaves, the relation between 
$\Psi O$ and the relative water content $(R w c)$ is necessary. $R w c$ is defined as follows: $R w c=(W s-V e) / W s$,

so Eq. 6 can be transformed to Eq. 8 in the following:

$$
\Psi o=\Psi o o \cdot\left(V_{o} / W_{s}\right) /\left[\left(V_{o} / W_{s}\right)-(1-R w c)\right]
$$

where $W s$ is the amount of water content at full turgor of a sample leaf in measurement $; \Psi \circ O$ is the osmotic potential at full turgor, that is, $\Psi_{O}=\Psi \circ O$ at $V e=0$.

On the other hand, pressure potential of leaves (Up) should be expressed also as a function of $R w c$. The equation was derived in the other report (Yahata, unpublished) to show that $\Psi p=-\Psi o o$ at $R w c=1$ and $\Psi p=0$ at $R w c=R w c^{*}$ where $R w c^{*}$ is the relative water content of leaves at the turgor loss point.

$$
\begin{aligned}
& \Psi p=-\Psi o o \cdot \sin ^{n}\left\{(\pi / 2) \cdot[1-(1-R w c)] /\left[(1-V p / V o) \cdot\left(V_{o} / W_{s}\right)\right]\right\} \\
& \text { at } R w c>R w c^{*} ; \\
& \Psi p=0 \\
& \text { at } R w c \leqq R w c^{*},
\end{aligned}
$$

where $\mathrm{n}$ is the constant specific to cultivar. $R w c^{*}$ is obtained in the following equation.

$R w c^{*}=1-\left(V_{o} / W_{s}\right)+\left(V_{o} / W_{s}\right)\left(V p / V_{o}\right)$.

It is well known that the stomatal apertures are dependent on the environmental condition such as incident light intensity, $\mathrm{CO}$, concentration, air temperature and water vapor deficit in the air, and regulated by the water status of leaves at the same time. As leaf conductance $(\mathrm{K})$ in Eq. 3 is naturally affected by these environmental condition, $K$ should be expressed as a function of these factors. There are two main method to obtain the function. One of them is to use the multiple regression for the data of the reciprocal of $K$, that is, leaf resistance as independent variables (Federer, 1979). The other is the multiple form of the environmental factors in the following equation, which was originally introduced by Jarvis (1976) (Federer, 1980), and modified here just putting the effect of the minimum value of leaf conductance at the stomata1 closure $\left(K c, \mathrm{~m}^{3} /(\mathrm{kgDw} \cdot \mathrm{s})\right)$ and considered to be useful because it is easy to reconstitute factors separately.

$$
K=K o \cdot F l \cdot F t \cdot F v \cdot F p+K c,
$$

where $K o$ is the maximum value of leaf conductance $\left(\mathrm{m}^{3} /(\mathrm{kgDw} \cdot \mathrm{s}) ; F l, F t, F v\right.$, and $F p$ are the factors of light, temperature, water vapor density deficit in the air, and leaf water stress, respectively, which vary from 0 to 1.

There are not available data so far to all cultivars concerning the relationships between the leaf conductance and the environmental factors except for cultivar Kumotooshi. In Kumotooshi, the relationship between light intensity (I) and heat pulse velocity $(\mathrm{Hpv})$ in the stem of the cuttings of two years old was obtained by Yahata and Harada (1975). As the Hpv could be used as an index of water flow rate and consequently an index of the leaf conductance supposing the leaf temperature had not affected by the light intensity, the data of $H p v$ will be used here instead of the direct measured data. The $H p v$ is related to light intensity (I) by the following equation.

$$
H p v=b \cdot I /(1+a \cdot I) \text {. }
$$

The maximum values of $H p v$ at the light saturation $\left(H p v_{\max }\right)$ can be derived by putting the infinite values of $I$ in Eq. 12 as in the following equation.

$$
H p v_{\max }=b / a \text {. }
$$

Then the light factor $F l$ which means the relative value of leaf conductance to the maximum at light saturation can be expressed as follows. 


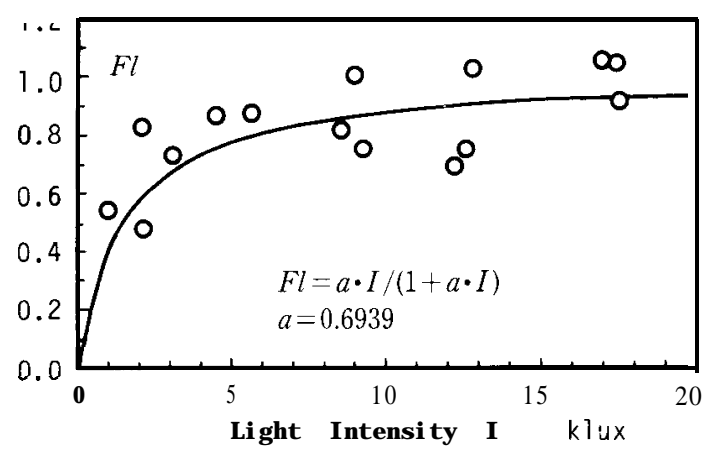

Fig. 2. Relationship between light intensity $(I)$ and light factor $(F l)$ indicated as a relative leaf conductance which is derived from the value of $\mathrm{Hpv} / \mathrm{Hpv}_{\max }$ measured by the heat pulse method (Redrawn after Yahata and Harada, 1975).

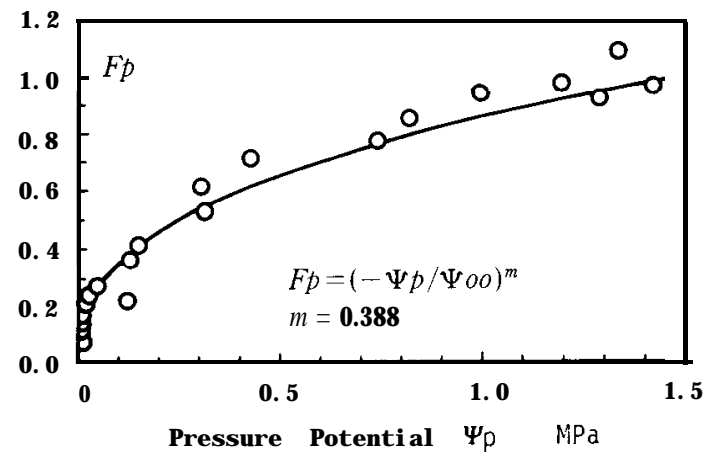

Fig. 3. Relationship between pressure potential $(\Psi p)$ and the factor $(F p)$ which is the relative leaf conductance measured by Yahata (1979).

$F l=H p v / H p v_{\max }=a \cdot I /(1+a \cdot I)$.

Fig. 2 shows the relation between light intensity and $F l$.

As relation between leaf conductance $K$ and pressure potential $(\Psi p$ ) were obtained by Yahata (1979) and the relation could be approximated to the power functions, $F p$ is also expressed as follows;

$F p=(-\Psi p / \Psi o o)^{m}$

where $m$ is constant. Fig. 3 shows the measured data by Yahata (1979) and the fitted regression curve.

The absolute water content of leaves per unit land area $\left(R w c \cdot W s \quad \bullet \quad D w, \mathrm{~kg} / \mathrm{m}^{2}\right)$ should increase or decrease at the interval of short time At depending upon the difference of the amount of the influx and efflux of water to and from the leaves, respectively. It is possible to take the time At short enough to make the transpiration rate(efflux) and water flow rate (influx) change almost linearly during the short period of At. Then, the following equation should be always valid.

$$
R w c_{2}=R w c_{1}+\left(Q_{1}+Q_{2}-E_{1}-E_{2}\right) \cdot \Delta t /\left(2 \cdot W_{s} \cdot D w\right),
$$

where $\mathrm{Q}$ and $E$ are the rates of water flow and transpiration, respectively, and the 
subscript numerals of 1 and 2 indicate the values at the time $t$ and at the time $t+\Delta t$, respectively.

As the direction of influence of a variable on another variable is illustrated in Fig. 1 , the related variables interact each other and it is seemingly difficult to get a solution. However, assuming that the relations shown in the series of equations from Eq. 2 to Eq. 16 except Eq. 12 and 13, are always strictly valid, it is possible to obtain the solutions of $R w c_{2}, Q_{2}, E_{2}$ that satisfy the series of equations. This can be easily solved by the Newton's methods in which, based on the initial guess of the root, it will attempt to make better and better approximations of the root by the following formula :

$x_{i+1}=x_{i}-f\left(x_{1}\right)\left[\left(x_{i}-x_{i-1}\right) /\left(f\left(x_{i}\right)-f\left(x_{1-1}\right)\right]\right.$,

in order to obtain $\left|x_{i+1}-x_{i}\right|$ smaller than a given value $\varepsilon_{0}$.

\section{APPLICATION TO THE SIMULATION MODEL}

Eight cultivars of Cryptomeria japonica at the age of 11 were selected for the measurement, which had been planted in a plantation in the nursery of Kyushu University, and shoots of the current year were used for the P-V curve technique in September and October, 1982 (Yahata, unpublished). The obtained results were shown in Fig. 4.

The objective of the report is to show the effect of the only leaf water relations parameters, the environmental factors such as light intensity $(I)$ and vapor density differences between leaf and air $(V d d)$ were calculated by the following equations to simulate the diurnal changes, respectively.

$V d d=V d d_{\max } \cdot \sin ^{2}(A-t / D)$,

$I=I_{\max } \cdot \sin ^{2}(\pi \cdot t / D)$,

where $D$ is the day length (s) ; $t$ is the time after sunrise (s) $; V d d_{\max }$ is the maximum value of the difference of water vapor between leaf and air $\left(\mathrm{kg} / \mathrm{m}^{3}\right)$ and $I_{\max }$ is the maximum light intensity (klux). During night time, both $V d d$ and $\mathrm{Z}$ were assumed to be equal to 0 . Here, the following values were used in the equations, respectively.

$V d d_{\max }=13 \times 10^{-3} \mathrm{~kg} / \mathrm{m}^{3}, I_{\max }=100 \mathrm{klux}, H c=7 \mathrm{~m}$, and $D w=2.0 \mathrm{~kg} / \mathrm{m}^{2}$.

The values of $a, K o$, and $m$ in Eq. 14 and 15 were obtained using the data of Kumotooshi as follows (Fig. 2, Fig. 3) :

$a=0.6939, K o=6.615 \times 10^{-6} \mathrm{~m}^{3} /(\mathrm{kg} \cdot \mathrm{s}), \boldsymbol{m}=0.388$.

The value of $K c$ is assumed to be equal to 0 , and the values of $F t$ and $F v$ are assumed to be stable and equal to 1 . The value of resistance to water flow $(R)$ was tentatively determined by trial and error so that the transpiration rates $(E)$ and leaf water potential $(\Psi l)$ fit the realistic tendency measured in the forest plantation and the following values were assumed for the resistance :

$R=5 \times 10^{6} \mathrm{MPa} \cdot \mathrm{s} / \mathrm{m}$ and $R=10 \times 10^{6} \mathrm{MPa} \cdot \mathrm{s} / \mathrm{m}$.

Calculation was done under a condition of the soil becoming drier from the saturated soil water, that is, $\Psi s=0 \mathrm{MPa}$ up to the drier soil, that is, $\Psi s=-1.4 \mathrm{MPa}(\mathrm{pF}=4.1)$ in the steps of $0.2 \mathrm{MPa}$ of water potential.

The soil water potential were assumed to be stable throughout the day. Before starting the calculation, at the time of sunrise, that is, $t=0$, the water movement is supposed to stop and have reached the equilibrium state between leaf and soil. Then, 

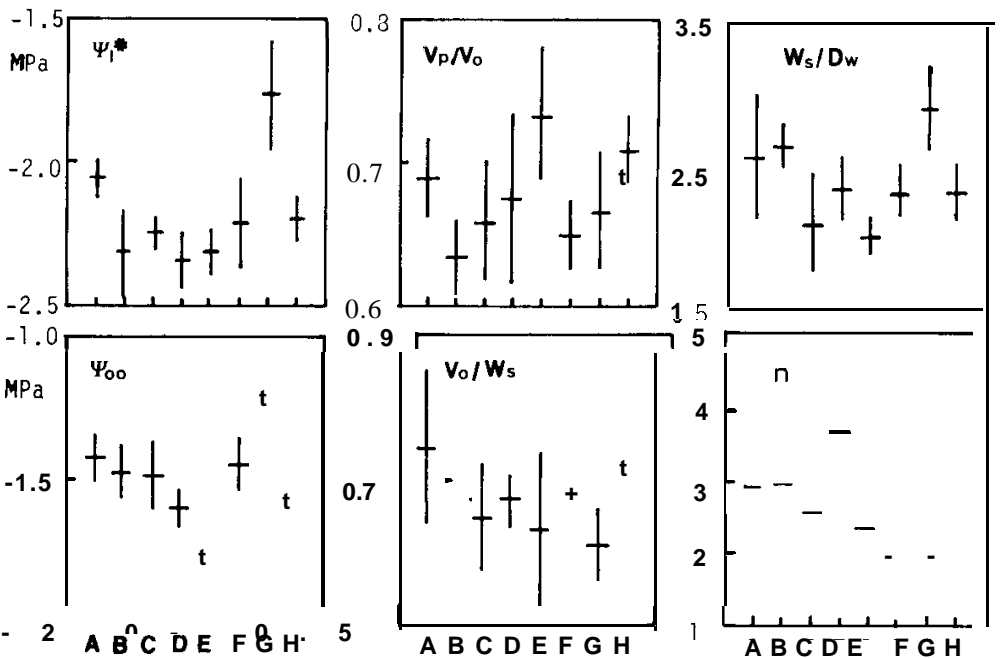

Fig. 4. Water relations parameters of the cultivars of Cryptomeria japonica. Vertical line indicates the confidence interval of population mean at $95 \%$ level. A, Kumotooshi ; B, Yaichi; C, Measa; D, Iwao; E, Kijin; F, Yabukuguri; G, Urasebaru; H, Ayasdgi.

kijin

Urasebaru

Kumotooshi

$\mathrm{R}=5 \times 10^{6} \mathrm{MPa} \cdot \mathrm{s} / \mathrm{m}$

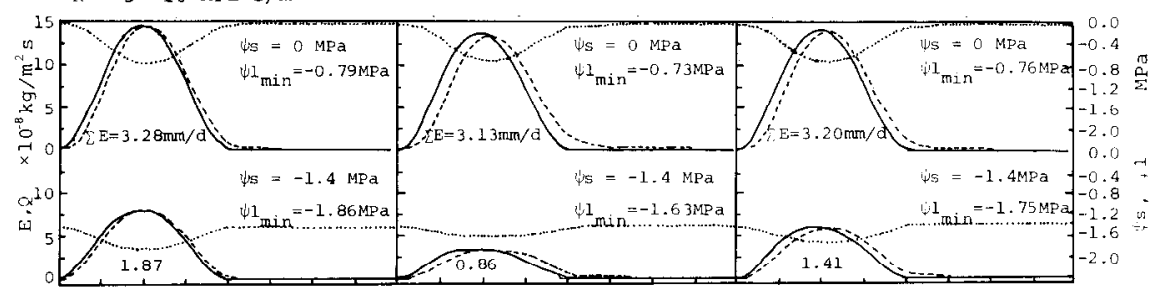

$R=10 \times 10^{6} \mathrm{MPa} \cdot \mathrm{s} / \mathrm{m}$

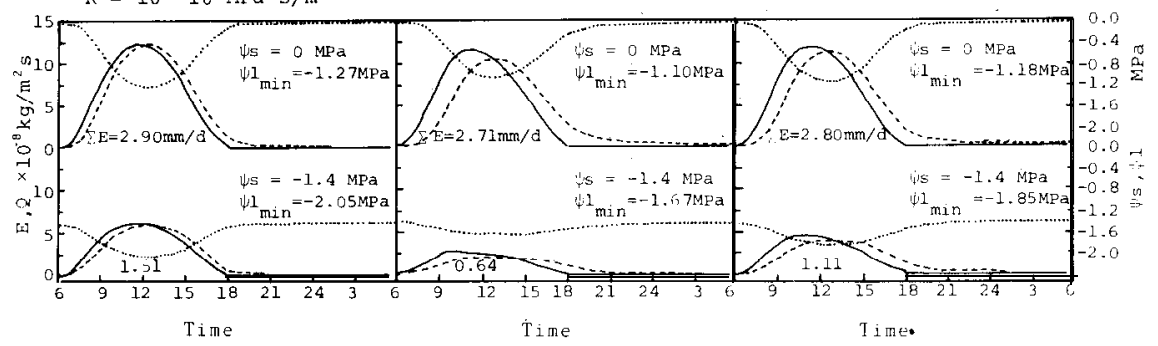

Fig. 5. Simulated results of water regime of Cryptomeria japonica plantation. Typical pattern of three cultivars (Kijin, Urasebaru, and Kumotooshi) among eight cultivars, two cases of soil water potential $(\Psi l)$ and water flow resistance $(R)$ are selected, respectively. Solid line, transpiration rate $(E)$; dashed line, water flow rate $(Q)$; and dotted line, leaf water potential $(\Psi l)$. 
$\Psi l$ was determined in the Eq. 4 by the input of $Q=0$. Calculation was made under the condition of day length $D=43200 \mathrm{~s}=12 \mathrm{hrs}$, calculation interval time At $=900 \mathrm{~s}$. A handheld computer (NEC PC-8201) and printer (NEC thermal printer PC-2021) were used for calculation and hard copy of the resulted figures, respectively.

\section{RESULTS AND DISCUSSION}

Fig. 5 shows only the selected results of the simulation to avoid the more complicated illustration, which were the most characteristic among all cultivars, that is, three cultivars of Kijin, Urasebaru and Kumotooshi and two cases of soil water potentials, $\Psi s=0 \mathrm{MPa}$ and $\Psi s=-1.4 \mathrm{MPa}$. In the figure, the minimum values of leaf water potential $\left(\Psi l_{\min }\right)$ and the daily total amount of transpiration $(\Sigma E)$ are also shown with the diurnal changes of transpiration rate $(\mathrm{E})$, water flow rate $(Q)$, and leaf water potentials $(\Psi l)$.

The delay of water flow into the leaves behind the transpiration resulted as shown Fig. 5 and the water flow continued until late at night even though the transpiration rates stop after sunset. These phenomena are often recorded in trees(Morikawa, 1974 ; Yahata, unpublished). It should be noted that the time lag differs clearly among cultivars. That is, it was greater in Urasebaru than in Kijin. This could be attributed to the large amount of $W s / D w$ and small reduction rate of $\Psi p$ in accordance to the reduction of $R w c$ in case of Urasebaru.

When calculated using the duplicated value of resistance $R$, the time lag of water flow behind the transpirations becomes conspicuous and in case of Urasebaru, the water flow continued until the following early morning. Although the lag of water flow has been considered to result mainly from the function of the stem as a water reservoir since the amount of water storage of stem is much larger than the one of leaves (Running, 1980), the result obtained here indicate that the leaves themselves could play an important role of water reservoir in water regime to cause the time lag.

The simulated values of leaf water potential and total amount of transpiration ranging from $3.13 \mathrm{~mm}$ to $3.28 \mathrm{~mm}$ in case or $R=5 \times 10^{6} \mathrm{MPa} \cdot \mathrm{s} / \mathrm{m}$ and $\Psi s=0 \mathrm{MPa}$ are considered to be close to the observed values (Yahata, unpublished). The drier the soil, the more limited the transpiration, and the pattern of the time course change of the transpiration showed a plateau. Furthermore, in case of $R=10 \times 10^{6} \mathrm{MPa} \cdot \mathrm{s} / \mathrm{m}$, the reduction of transpiration occurs early in the afternoon and the symmetrical pattern of daily course changes broke by a severe water stress.

The most interesting result is that the reduction of transpiration rate caused.by the soil water stress was conspicuous in Urasebaru than in Kijin.

In order to show the reduction of daily total amount of transpiration caused by the reduction of soil water potential, Fig. 6 shows the ratio of amount of transpired water to the one under the condition of $\Psi s=0 \mathrm{MPa}$. The reduction rate of the relative amount of daily transpiration caused by the lower soil water potential was much greater in Urasebaru, followed by Kumotooshi and Ayasugi, than the cultivars such as Kijin, Yabukuguri, Iwao, Yaichi, and Measa.

The photosynthetic rate which is closely related to the plant growth (Yahata et al., 1979 ) is affected by many environmental factors. Among all of them, the stomata1 


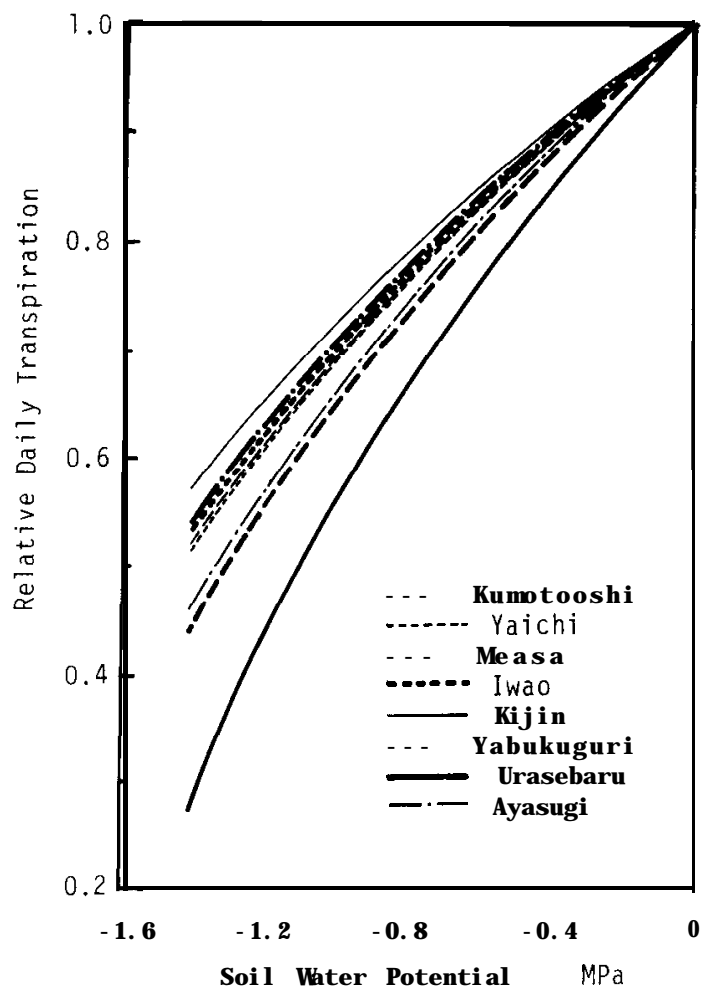

Fig. 6. Calculated relationship between soil water potential $(\Psi s)$ and relative daily transpiration $\left(\Sigma E / \Sigma E \Psi_{s=0}\right)$.

aperture which is indicated as leaf conductance could regulate both the flow rates of transpiring water vapor and $\mathrm{CO}$, gas through the stomata. Although the rates of photosynthesis and transpiration are affected by the different environmental factors, respectively and consequently both rates would not be always proportional, the linear relation between the both rate could be expected as far as the other environmental conditions are stable except for soil water potential. Furthermore, the relation between the daily total amount of transpiration and photosynthesis of the same tree would be proportional when the diurnal patterns of changes of the environments are same although the diurnal changes of environmental factors occur. Therefore, it could be inferred by Fig. 6 that the photosynthetic rate of Urasebaru would decrease much greater than that of Kijin. The same things could be inferred as to tree growth. There are many reports that Urasebaru is one of the most sensitive cultivars to site classes (Sato et al., 1971; Oikawa and Kawano, 1960 ; Miyajima, 1973 ; Kawano and Masuda, 1979). Although the sensitivity to site classes includes the effect of nutrient response of cultivars, it is suggested that the water relations characteristics of leaves play an important role in the response to the site.

An experiment to determine both the rates of transpiration and photosynthesis was made by changing the soil water potential in potted two years-old cuttings of the 
same cultivars except for Measa, and the similar results were obtained (Yahata et al., 1986). Checking the simulated values with observed values is still necessary by putting the whole data of specific variables to each cultivar and the simulation model shown in this report could be modified into more complicated one. It should be noted, however, that, because of the simulation, it is possible to check the significance of the water relations parameters of the cultivars on the water regime and thus obtained parameters could direct to the breeding for greater drought resistance.

\section{ACKNOWLEDGMENT}

The author would like to thank Professors H. Miyajima and T. Suzaki for helpful comments and critical reading of the manuscript.

\section{REFERENCES}

Federer, C. A. 1979 A soil-plant atmosphere model for transpiration and availability of soil water. Water Resour.Res., 15: 555-562

Federer, C. A. 1980 Paper birch and white oak saplings differ in responses to drought. For. Sci, 26 : 313-324

Jarvis, P. G. 1976 The interpretation of the variations in leaf water potential and stomatal conductance found in canopies in the field. Philos. Trans. R. Soc. London, Ser. B, 273 : 593-610

Kawano Y. and T. Masuda 1979 Examination on adaptability of the cultivars of Cryptomeria japonica to the practical fields (I) On the growth at 20 years old. Bull. Kyushu Branch Jap. For. Soc., $32: 167-168$ (in Japanese)

Miyajima H. 1973 Approach to intensive culture and forest tree breeding of Cryptomeria japonica. Bull. Kyushu Univ. For., 47: 13-20

Morikawa Y. 1974 Sap flow in Chamaecyparisobtusa in relation to water economy of woody plants. Tokyo Univ. For. Bull. 66: 251-297

Oikawa, Y. and T. Kawano 1960 Environments and growth of the cultivars of Cryptomeria japonicu (II) Sites and growth of cultivars Urasebaru and Yabukuguri. Bull. Kyushu Branch Jap. For. Soc. 14 : 75-77 (in Japanese)

Running, S. W. 1980 Relating plant capacitance to the water relations of Pinus contorta. For. Ecol. Manage.,2: 237-252

Sato, K., H. Miyajima, T. Suzaki and K. Nogami 1971 Report of Research and Study on the Cultivars of Cryptomeria japonica in Kyushu and Their Characteristics, Kumamoto Regional Forest Office, Forestry Agency (in Japanese)

Tan, C. S., T. A. Black, and J. U. Nnyamah 1978 A simple diffusion model of transpiration applied to a thinned Douglas-fir stand. Ecology, $59: 1221-1229$

Tyree, M. T. and H. T. Hammel 1972 The measurement of the turgor pressure and the water relation of plants by pressure technique. J. exp. Bot., $23: 267-282$

Yahata, H. and H. Harada 1975 The effects of some environmental factors on transpirational water flow in some trees, Bull, Kyushu Branch Jap. For. Soc., 28:117-118 (in Japanese)

Yahata, H. 1978 Water relations characteristics of Cryptomeria japonicu (I) Method to determine the leaf water relations parameters using the pressure chamber. Bull. Kyushu Branch Jap. For. Soc., $31: 115-116$ (in Japanese)

Yahata, H. 1979 Water relations characteristics of Cryptomeria japonica (II) Relationship between stomata1 closure, water potential and relative water content, Trans. 90th Mtg. Jap. Far. Soc., 269270 (in Japanese)

Yahata, H., T. Suzaki and H. Miyajima 1979 Some methods to estimate parameters on relating 
photosynthesis to tree growth and application to Cryptomeria japonica. J. Jap. For. Soc., 61 : 151162

Yahata, H., Y. Sado and H. Miyajima 1986 Water relations characteristics of Cryptomeria japonica (V) Validity test of the simulation model of water regime with seedlings of several cultivars. Bull. Kyushu Brunch Jap. For. Soc., 39: 49-50 (in Japanese) 